6-1-2021

\title{
Maxillofacial prosthodontists are needed for the rehabilitation of patients with congenital and acquired craniofacial defects
}

Syed Murtaza Raza Kazmi

Farhan Raza Khan

Follow this and additional works at: https://ecommons.aku.edu/ pakistan_fhs_mc_surg_dent_oral_maxillofac

Part of the Dentistry Commons, and the Surgery Commons 


\section{Maxillofacial prosthodontists are needed for the rehabilitation of patients with congenital and acquired craniofacial defects}

Syed Murtaza Raza Kazmi, Farhan Raza Khan

Maxillofacial Prosthodontics (MFP) is a super-specialty of prosthodontics that revolves around rehabilitation of the patients presenting with congenital maxillofacial defects or craniofacial disabilities acquired due to diseases such as cancer or trauma. ${ }^{1}$ There are several types of prostheses that can be designed and fabricated by a maxillofacial prosthodontist to improve the quality of life of the patients. A simple classification is shown in figure.

Maxillofacial prostheses are required to replace the missing oro-facial tissues with an objective of restoring chewing, swallowing and speech. In addition to restoring the above functions, an important indication of maxillofacial prosthesis is maintenance of the facial features of the affected individual. Anatomical or functional loss of facial tissues has significant bearing on the psychosocial lives of the affected individuals. Maxillofacial prostheses help to improve the patients' quality of life. ${ }^{2}$

MFP is performed by dentists who have received additional training in this domain. At present, the most suitable dentists to offer such care are prosthodontists who have relevant experience and interest in offering this service. Owing to the nature of the work, an MFP clinician has to be

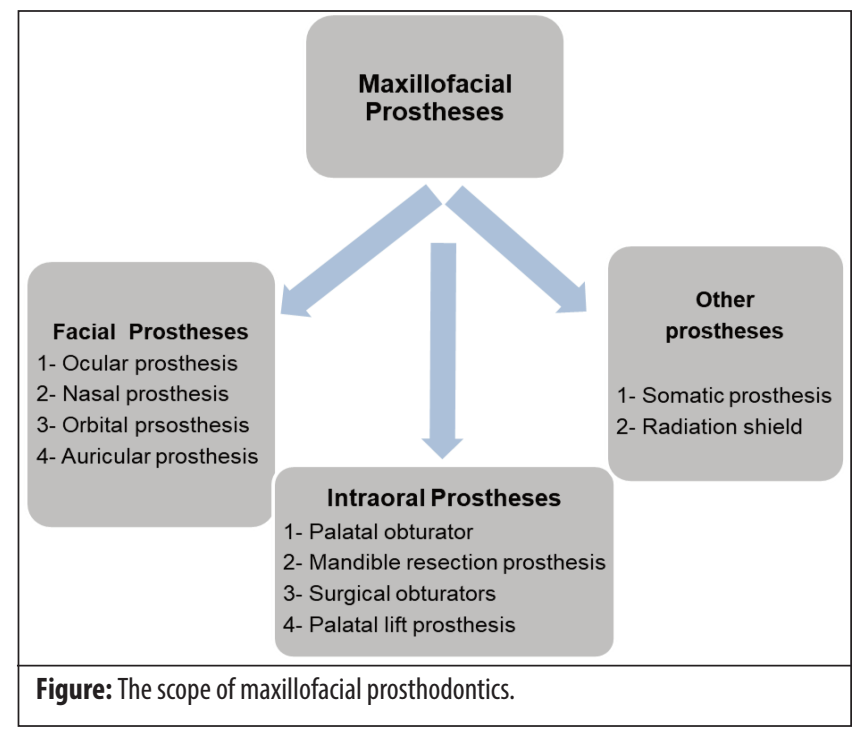

Department of Surgery, Aga Khan University, Karachi, Pakistan.

Correspondence: Farhan Raza Khan. e-mail: farhan.raza@aku.edu a team player who is willing to work along with ENT, head \& neck, oral and maxillofacial surgeons, plastic surgeons, radiation oncologists, speech therapist, psychologist, nutritionists and dental laboratory technicians. All these are directly or indirectly involved in the management, especially of head and neck cancer patients. ${ }^{2}$

Pakistan is a country where use of tobacco is prevalent (mostly because of social and cultural reasons). Pakistan is one of the largest tobacco consumers in the South Asian region. ${ }^{3}$ Hence, oral cancerous and pre-cancerous conditions are on the rise. Chaudhry et al reported that head and neck cancer comprises $14.5 \%$ of all cancers and is the second most common cancer in Pakistan. ${ }^{4}$ Lung cancer among males and breast cancer among females are on top of the list. People of India, Pakistan and Bangladesh, probably due to their social, cultural and eating habits, are predominately prone to oral cancers.

One of the main congenital dentofacial problems in Pakistan is cleft lip and palate. At least one in every 700 live births have such clefts. 5 In Pakistan, most of these patients merely get their cleft lip repaired by plastic surgeons at public hospitals or health camps but unfortunately the anatomic defect in the bony palate remains unattended. The functional rehabilitation of cleft lip and palate patients remains far below the standard care.

Due to factors such as lack of education, lack of resources and difficulty in accessing medical care, the patients present quite late to the health service provider. Unfortunately, such patients end up undergoing surgical resection and radiation therapy of the head \& neck region. There are excellent surgeons and radiation oncologists available in the tertiary care centres of the country to manage these patients. However, it has been observed that the post-surgical dental rehabilitation of such patients is poorly managed. It is important to note that head and neck cancer patients often undergo maxillectomy or mandibulectomy (total or sub-total) followed by radiation therapy. Surgery creates anatomical and functional facial defects which not only disfigures the patients but also adversely affects their chewing, swallowing and speech abilities. To make things worse, the post-operative radiation therapy further deteriorates saliva production, making 
swallowing even more difficult, and often causes trismus. Lack of saliva makes the remaining teeth vulnerable to dental caries. The post-surgical scarring along with trismus makes routine oral hygiene care next to impossible. All of this adds to the misery of the patient who suffers a progressive loss in nutrition as well. All clinicians would emphasise the role of prevention in cancers; however, for those who are already affected with this debilitating disease, the best management is multi-disciplinary care. The focus should be on improving the quality of life of the patient and the MFP has a pivotal role in achieving the same. 6

It is unfortunate to learn that at present, in the entire province of Sindh, there are only three centres which offer prosthodontics residency training under the supervision of College of Physicians and Surgeons, Pakistan (CPSP). A few MDS programmes are training prosthodontists as well. Altogether, there is an acute dearth of prosthodontists who can offer MFP education and services. This needs to be taken up seriously as this is a national need. But how many maxillofacial prosthetics specialists does Pakistan need? The answer is not known. Ariani et al ${ }^{6}$ argued that there are no set recommendations regarding the number of maxillofacial prosthodontists; the need may be different in different countries depending on the burden of the disease.

There is no dedicated MFP training centre or facility in Pakistan, let alone Sindh. It's high time that the provincial and central governments, and the dental fraternity come together and identify the prosthodontist(s) who are willing to take active lead in acquiring the expertise in this domain and further train the emerging prosthodontists to develop the required competency in this area of practice.

Sheets et al reported that in the USA, the duration of prosthodontics residency was increased from two years to three years in 1966 and later one year fellowship in MFP was introduced.7 Following the North American model, 8 university hospitals in Pakistan should establish postresidency fellowship training. This training can be treated as a second fellowship diploma in the subspecialty at the College of Physicians and Surgeons of Pakistan.
A post residency training in MFP will produce competent clinicians to manage the rehabilitation of patients with congenital defects (such as cleft palate) and acquired defects, especially among survivors of head \& neck cancer. This will also improve the quality of head and neck tumour boards. Tumour boards are multidisciplinary team meetings in which different specialists work together for making clinical decisions regarding the care of cancer patients. MFP trained dentists can be important contributors in the rehabilitation of head and neck cancer patients.

Keywords: Prosthodontics; maxillofacial prosthodontics; maxillectomy, cleft lip; cleft palate.

Disclaimer: None.

Conflict of Interest: None.

Funding Sources: None.

DOI: https://doi.org/10.47391/JPMA.419

\section{References}

1. Schaaf NG. Maxillofacial prosthetics and the head and neck cancer patient. Cancer 1984; 54(11 Suppl): 2682-90.

2. Goiato MC, Pesqueira AA, Ramos da Silva C, Gennari Filho H, Micheline Dos Santos D. Patient satisfaction with maxillofacial prosthesis. Literature review. J Plast Reconstr Aesthet Surg 2009; 62: 175-80.

3. Malhi W. Pakistan's tobacco consumption: The most in South Asia. Pakistan Today. 2013, February 8.

4. Chaudhry S, Khan AA, Mirza KM, Iqbal HA, Masood Y, Khan NR, et al. Estimating the burden of head and neck cancers in the public health sector of Pakistan. Asian Pac J Cancer Prev 2008; 9: 529-32.

5. Dixon MJ, Marazita ML, Beaty TH, Murray JC. Cleft lip and palate: understanding genetic and environmental influences. Nature Rev Gen 2011; 12: 167-78.

6. Ariani N, Visser A, van Oort RP, Kusdhany L, Rahardjo TB, Krom BP, et al. Current state of craniofacial prosthetic rehabilitation. Int J Prosth 2013; 26: 57-67.

7. Sheets JL, Pinkston DJ, Yuan JC, Sukotjo C, Wee AG. US Maxillofacial Prosthetics Programs: Fellows' and Directors' Perspectives. J Dent Educ 2018; 82: 1335-42.

8. Mayo Foundation for Medical Education and Research. Maxillofacial Prosthetics and Dental Oncology Fellowship (Minnesota). [Online] [Cited 2020 March 16]. Available from: URL: https://college.mayo.edu/academics/residencies-andfellowships/maxillofacial-prosthetics-and-dental-oncology-fellowship-minnesota/. 